\title{
Exercise Addiction in the Sports Context: What Is Known and What Is Yet to Be Known
}

\author{
Débora Godoy-Izquierdo ${ }^{1,2}$ (ID) Estefanía Navarrón ${ }^{2} \cdot$ Clara López-Mora $^{3}$. \\ Juan González-Hernández ${ }^{1,2}$
}

Accepted: 23 August 2021 / Published online: 24 September 2021

(c) The Author(s) 2021

\begin{abstract}
Exercise addiction (EA) involves excessive concerns for exercise routines, an abusive practice, and the inability to control one's own behavior, as well as the presence of psychological processes that are typical of behavioral addictions such as abstinence. EA is further associated with an alteration of the individual's personal, social, and professional functioning and a higher risk for several pathologies, including physical injury, psychological distress, and eating disorders. The present work presents a narrative scoping review of the state of the art and the main findings of the research on EA, with a focus in the athletic population. The prevalence of EA risk, between 1 and 52\% and up to $80 \%$ when co-occurring with eating disturbances, is also reviewed. Additionally, some of the explanatory models proposed to date and their power and limitations in terms of their capacity for a consensual operationalization and characterization of EA, and thus for the optimal exploration and management of this condition, are discussed. Finally, some deficiencies in the research on EA are noted which are to be addressed to successfully respond to the intervention and prevention needs that occur both in the general context of exercise-sports practice and the specific context of competitive athletes.
\end{abstract}

Keywords Exercise addiction $\cdot$ Athletes $\cdot$ Behavioral addiction $\cdot$ Mental health $\cdot$ Sport

Mental health in sports is receiving increasing attention, and the most prominent institutions and organizations in Sport Psychology and other fields have elaborated their own position statements regarding comprehensive mental care for athletes (e.g., Chang et al., 2020; Henriksen et al., 2019; Moesch et al., 2018; Reardon et al., 2019; Schinke et al., 2018). Simultaneously, mental health issues in athletes are often hidden by the sufferers,

Débora Godoy-Izquierdo

deborag@ugr.es

1 Department of Personality, Assessment \& Psychological Treatment, Faculty of Psychology, University of Granada, Granada, Spain

2 Research Group "Health Psychology \& Behavioral Medicine” CTS267, University of Granada, Granada, Spain

3 Seneca Foundation \& Department of Human Development and Family Science, College of Human Environmental Sciences, University of Missouri, Columbia, MO, USA 
e.g., athletes, technicians and clubs, for fear of shame and stigma. While the prevalence of mental ill conditions among athletes is still under debate, growing evidence has accumulated showing that high-performance athletes are not as protected from mental disorders as previously thought. The clinical differences of athletes in comparison with the general population are important for the diagnosis, therapy, and prevention of mental disorders to meet the special needs and experiences of athletes suffering from mental and behavioral disturbances. These specificities should be taken into account by athletes and coaches as well as by sports psychologists and psychiatrists caring for athletes with mental and behavioral dysfunctions.

\section{Exercise Addiction, Exercise Dependence, Abusive Exercise, and Other Forms of Problematic and Unhealthy Exercise}

Exercise addiction (EA) describes a condition of excessive or abusive exercising behavior in which moderate to intense physical activity becomes a compulsive behavior (i.e., preoccupation with exercise routines, over-exercising, and inability to control the exercising behavior). The individual is driven or compelled to continuing exercise for longer and more regular periods, i.e., excessive amounts of exercise, to the detriment of his or her personal, social, and professional life and regardless of harmful health consequences, while even ignoring clinical advice or training while exhausted, injured or ill; in addition, when abstaining from training, the individual shows the typical withdrawal symptoms that characterize behavioral addictions (Adams, 2009; Adams \& Kirkby, 1998; Lichtenstein et al., 2017; Marques et al., 2019; Trott et al., 2020; Veale, 1987; Yates et al., 1983). EA has been defined as a craving or rigid and extreme urge for physical activity that leads to highly intense exercise and generates physiological and psychological adverse manifestations and symptoms (Meyer et al., 2011; Petit \& Lejoyeux, 2013), including overtraining and chronic fatigue, bodily pain, injuries, doping, stress, depression, sleep dysfunction, and disordered eating, as well as performance impairments. Thus, it is a "morbid pattern of behavior in which the habitually exercising individual loses control over his or her exercise habits and acts compulsively, exhibits dependence and experiences negative consequences to health as well as in his or her social and professional life" (Szabo et al., 2015, p. 303).

More specifically, EA refers to a multidimensional maladaptive pattern of exercise that is associated with significant distress and impairment and characterized by the following (Hausenblas \& Symons Downs, 2002a): (1) tolerance to increased exercise amounts, (2) withdrawal effects when exercise is not undertaken, (3) intention effects resulting in recurrent and longer involvement, (4) lack of control in engaging or reducing behavior, (5) excessive time spent in exercising or related behaviors, (6) reductions in other activities because of exercise, and (7) the continuance of exercise despite recurrent physical or psychological problems. Hausenblas and Symons Downs (2002a) proposed that the presence of at least three of the previous symptoms evidenced exercise dependence.

Accompanying this diversity of definitions, a plethora of terms has been used to define this maladaptive engagement in physical activity (e.g., exercise addiction, exercise dependence, obligatory/excessive/abusive/compulsive exercise, exercise misuse/abuse), making the interpretation of the literature challenging; since each term has specific features and connotations (e.g., implication of pathology and problematic categorizing of individuals from a pathology-based definition), it has been proposed that the term EA encompasses all, as it might gather all the meanings (e.g., Berczik et al., 2012; Cook et al., 2014; Freimuth et al., 
2011; Hausenblas \& Symons Downs, 2002a; Lichtenstein et al., 2017; Petit \& Lejoyeux, 2013; Szabo, 2009; Szabo et al., 2015, 2018; Weinstein \& Weinstein, 2014). This proposal also coincides with the most frequent characterization of excessive behaviors: $75 \%$ of the studies focusing on excessive exercise adopted the frame of addiction conceptualization (e.g., Mudry et al., 2011), yet others have found that "exercise dependence" is more frequently used to refer excessive exercise (e.g., Gonçalves et al., 2019).

Usually-but not uniquely-expressed as a continuum instead of a discrete entity, EA begins with a search for pleasure or performance goals in physical effort (i.e., recreational exercise, athletic training), which then gives way to an obsession for exercise resulting in a need to practice it more and more frequently and intensely (i.e., problematic, at-risk exercise leading to addiction) (Elbourne \& Chen, 2007; Freimuth et al., 2011; Gapin \& Petruzzello, 2011; Meyer \& Taranis, 2011; Petit \& Lejoyeux, 2013; Weinstein \& Weinstein, 2014). Thus, it seems there is a developmental pathway that leads from exercising for fun ("want to") to an increasing commitment to exercise ("have to") and finally to a psychophysiological dependence on exercise ("must to") that is no longer linked to enjoyment or performance goals (Gapin \& Petruzzello, 2011; Zeeck et al., 2017). Supporting this continuum, Cook et al. (2013) and Magee et al. (2016) found in athletes several subgroups graded by type and severity of symptoms by using both cut-off points and clustering techniques for within-subject profiles. Some other empirical findings support the conceptualization of EA as a continuum by finding different results for different ranges of EA (e.g., Gorrell \& Anderson, 2018). Moreover, qualitative research on the self-narratives of problematic exercise also supports the continuum (e.g., Johnston et al., 2011). Thus, it seems there is not only the chance to categorize individuals as being either dependent/ nondependent but also as having a variety of levels of risk and EA manifestations.

Despite the negative health effects that can be associated with excessive exercise, including increased physical and mental illness, injury, and particularly disordered eating and eating disorders, evidence has shown that individuals with EA show unremarkable levels of psychological morbidity and do not report sufficient psychological distress to warrant classifying EA as a pathology or including EA in nosological classifications such as the Diagnostic and Statistical Manual of Mental Disorders, 5th Edition (DSM-5), or the International Classification of Diseases, 11th Edition (ICD-11), as a separate disorder with its own entity, although the lack of sustained and methodologically rigorous evidence may profoundly contribute to this insufficiency (Marques et al., 2019; Szabo et al., 2015). The more recent DSM-5R still incorporates EA among nonsubstance-related behavioral addictions, which are included alongside substance use disorders. Dependence on exercise can be considered an addictive behavior because it presents signs that are typical of other addictive behaviors, such as loss of control over the behavior, mood disturbances, and tolerance and abstinence syndrome, and dedicating too much time to the behavior, with interferences in life and relapses (Cook et al., 2014; Marques et al., 2019).

As an addiction, exercise dependence can be primary, i.e., exercising is an end in itself, such that the behavior is intrinsically rewarding and gratifying, and individuals are motivated for the psychological gratification resulting from the compulsive exercise behavior itself, or it can be secondary, such that the individual is driven to exercise to accomplish a separate outcome, as occurs when he or she exercises to facilitate an eating or a body image dysfunction, i.e., a symptom of an eating disorder (Veale, 1987). In its form of secondary to psychopathology, exercise is used as a compensatory behavior in an attempt to lose weight, balance calories, control body composition, and enhance one's physical appearance such that it exacerbates symptoms and consequences related to eating-related disturbances. Since the very early studies that focused on the sports arena, primary and 
secondary exercise dependence have been proven to be distinct and independent conditions (e.g., Blaydon et al., 2002, 2004; Cook \& Luke, 2017; Cook et al., 2013; Cunningham et al., 2016). However, the existence of EA as a secondary dependence has been debated (see Cook et al., 2014; Szabo et al., 2015). In contrast, other scholars have stated that EA and eating disorders cannot exist independently from one another at all, meaning that EA is always secondary (see Adams, 2009; Elbourne \& Chen, 2007; Lichtenstein et al., 2017). As recent reviews have showed (e.g., Godoy-Izquierdo et al., 2021, in this Issue; Gonçalves et al., 2019), there exists a commitment to excessive exercise that is clearly related to weight and shape preoccupation, weight control, dietary attitudes and behaviors, and body image issues.

Research on EA started in the 1970s, grew in the 1980s to the 2000s, and exploded until recently; it is currently a well-recognized although poorly understood and controversial phenomenon for which investigation is still inconsistent (e.g., Adams, 2009; Adams \& Kirkby, 1998; Allegre et al., 2006; Berczik et al., 2012; Cook et al., 2014; Davis, 2000; Freimuth et al., 2011; Gonçalves et al., 2019; Hausenblas \& Symons Downs, 2002a; Kerr et al., 2007; Lichtenstein et al., 2017; Petit \& Lejoyeux, 2013; Szabo et al., 2018; Veale, 1987; Weinstein \& Weinstein, 2014). However, knowledge has been based on a lack of well-controlled empirical evidence (Gonçalves et al., 2019; Hausenblas \& Symons Downs, 2002a; Szabo, 2009; Szabo et al., 2015) and, more importantly, the absence of a consensus on the nomination, definition, operationalization, identification, and measurement of EA manifestations and etiological and outcome correlates, along with issues on evidence-guided diagnosis and clinical practice. In addition, there is a neglect of the multiple and varied subjective experiences of those suffering from EA. Moreover, EA has been mainly approached in contexts outside the sports arena, such as regular exercisers and fitness center users, clinical samples of patients with eating disorders or the general population, mostly including university students (see Cook et al., 2013; Gonçalves et al., 2019). Nevertheless, sports-specific risk factors have been proposed from the beginning, such as involvement in endurance sports (e.g., Di Lodovico et al., 2019; Kerr et al., 2007; Nogueira et al., 2018). As athletes are a high-risk subgroup for EA due to the amount of practice and the demands of the competitive context, a focus will be given to this condition in the athletic population.

\section{EA: Who Is Affected and How? Prevalence and Sporting Features}

An inconsistency has also been observed in reporting the prevalence of EA. Among regular exercisers and community samples, EA affects 2-43\% of individuals (see Cook et al., 2014; Cook \& Luke, 2017; Di Lodovico et al., 2019; Simón-Grima et al., 2019; Szabo et al., 2015; Zeeck et al., 2017). The most incredible figures indicate prevalence rates that can reach $80 \%$ of the general population and leisure exercisers (Egorov \& Szabo, 2013; Petit \& Lejoyeux, 2013; Trott et al., 2020). Moreover, Szabo et al. (2019) found a nonsignificantly different prevalence rate of $11.5 \%$ using the EAI (with the scoring rating scale changed from original) and $9 \%$ with the EDS-R in a sample of exercisers, and only a $88 \%$ of concordance between both tools for identifying the individuals who were at risk, symptomatic and asymptomatic; such discrepancies have been also previously found (e.g., Mónok et al., 2012). All these findings support that the measurements being used are probably assessing related but not totally identical psychological constructs. 
Among athletes of diverse sports and performance levels, rates have been reported to range from 3 to $41 \%$ (see Magee et al., 2016; Szabo et al., 2015). Research on the prevalence of EA has focused mostly on individual sports; specifically, among endurance athletes such as runners and triathletes, estimates range from 3 to 77\% (see Cook et al., 2013; Cook \& Luke, 2017; Di Lodovico et al., 2019; Gapin \& Petruzzello, 2011; Nogueira et al., 2018). In team and ball sports, for instance, $7-18 \%$ incidence rates in football have been found (Costa et al., 2015; Di Lodovico et al., 2019; Lichtenstein et al., 2014), but others report up to $28 \%$ prevalence (Modolo et al., 2011). Godoy-Izquierdo et al. (2021, in this Issue) found prevalence estimates between 1 and 59\% for a wide range of sports types and levels of competition; the figures are 1-51\% for runners, $30 \%$ for triathletes, $8-9 \%$ for ironman and cycling athletes, and $15-30 \%$ for athletes in a nondisaggregated variety of sports. Two studies disaggregated prevalence rates by gender; in both running and a variety of sports, women were between 55 and $67 \%$ more likely to report EA. Moreover, one study specifically distinguished between lean (40\%) and nonlean (26\%) sports for calculating the prevalence of EA among female athletes.

Recent meta-analytic research estimates that $13 \%$ of the active population-including but not uniquely athletes-may suffer from EA (Simón-Grima et al., 2019), with a range between 1 and 52\% (Gonçalves et al., 2019). Another meta-analysis (Marques et al., 2019) reported a prevalence of 3-7\% among regular exercisers and of 6-9\% in the athlete population, yet estimates ranged from 1.4 to $17 \%$ for the latter, suggesting a slightly higher risk among the athlete population compared to the general population. Marques et al. (2019) also found that EA had been examined in just 11 studies among the athletic population, with only one study reporting findings for primary and secondary risk for EA: primary EA was found in $8 \%$ of athletes, while secondary EA was observed in $1 \%$.

However, in a recent review, Godoy-Izquierdo et al. (2021, in this Issue) found more studies exploring the prevalence of secondary EA, with overall prevalence rates ranging from 1 to $80 \%$. Differentiating by sports, rates are $31-80 \%$ for runners, $22 \%$ for triathletes, $1 \%$ for cyclers, and $13-57 \%$ for athletes in a nondisaggregated variety of sports. None of the studies disaggregated prevalence rates by gender or lean vs. nonlean types of sports. Comparatively, two studies showed a nearly $30 \%$ points higher prevalence of EA co-occurring with eating pathology compared to pure EA, whereas another study found similar rates for both conditions, and only one found a difference of $8 \%$ points favoring the prevalence of pure EA.

The discrepancies in the prevalence figures could reflect differences in a number of contextual, sports or athletes' individual risk factors as well as methodological problems (e.g., measures used to assess EA, classification algorithms or decisions on diagnostic criteria) (e.g., Berczik et al., 2012; Cook et al., 2014; Gonçalves et al., 2019; Lease \& Bond, 2013; Magee et al., 2016; Szabo et al., 2015; Trott et al., 2020). Simply stated, the varying sample characteristics and assessment tools may be limiting our understanding of EA (Cook et al., 2013). Indeed, in a sample of ironman athletes (Magee et al., 2016), it was found that $9 \%$ could be considered at risk for EA, $79 \%$ could be considered as nondependent but symptomatic, and only $12 \%$ could be considered as nondependent and asymptomatic based on scoring criteria and cut-off points; however, when using profile analytic techniques, while the majority of athletes appeared to have a healthy involvement with sports and may derive positive health and well-being outcomes from their training and participation in competition, approximately $30 \%$ belonged to the at-risk and symptomatic profiles, which could reflect maladaptive patterns of exercise.

Moreover, these figures are based on self-report measures as screening instruments, which inform on the risk of having EA, but only a small percentage of these "at-risk" 
individuals would fulfill the criteria based on the diagnostic symptoms for addiction or dependence in a clinical interview (Zeeck et al., 2017). In addition, voluntary participation in research on EA probably introduces sample bias, as individuals with unhealthy behaviors are less likely to collaborate (Magee et al., 2016). Consequently, prevalence rates may be both overestimated and underestimated.

Additionally, there is an increasing number of individuals in the general population exercising as athletes. Competitions in many sports, such as running disciplines, ball or racquet sports, and weightlifting, have attracted recreational athletes who participate for a variety of reasons but for whom there was no planned athletic career or supervision by professionals. With increases in their participation in athletic events with true athletes, it is plausible that a greater number of individuals among this recreational population may increasingly identify with the athletic model and potentially make an effort to control their performance. Consequently, given the prevalence rates of EA, a potentially large number of recreational athletes could be increasingly engaged in compulsive exercise to control performance, as well as to decrease or suppress negative affectivity such as anxiety or guilt when not able to exercise, or to manage eating and bodily dimensions. Given that these recreational athletes do not have the formation, monitoring, counseling, and control that professional athletes have, they can be at a particular risk. Thus, there is a distinct need for increased clinical screening, prevention, and management of factors that may precipitate or exacerbate vulnerability for EA in this population (Gorrell \& Anderson, 2018). Improved understanding of this reality may help to identify for whom the relation between exercise - and eating - pathology may be most problematic and to inform screening and clinical interventions.

\section{How Can EA Be Accurately Identified, Especially in Athletes?}

Before we can derive a comprehensive conceptual model of EA for designing interventions aimed at preventing and managing this condition, a consensual operationalization and characterization of addiction to exercise is needed for its optimal measurement and exploration. Inconsistencies and a lack of consensus in both terminology and operational description across the literature occlude the establishment of a clear definition of precisely for whom and when a pattern of exercise behavior becomes problematic (Gorrell \& Anderson, 2018; Meyer \& Taranis, 2011; Szabo et al., 2015).

As already mentioned, there is a lack of consensus pertaining to the measurement of EA (Gonçalves et al., 2019; Lichtenstein et al., 2017; Szabo et al., 2015) (see Table 1 for a brief presentation of the main tools used for assessing EA). While the earlier Obligatory Exercise Questionnaire (OEQ) and the Exercise Dependence Questionnaire (EDQ) were not based on a conceptual background, the Exercise Addiction Inventory (EAI) has an underlying theory of behavioral addictions, and the Exercise Dependence Scale (EDS and EDS-R) is based on the DSM-IV criteria for substance abuse. As Cunningham et al. (2016) and Trott et al. (2020) demonstrated, the diverging average scores and prevalence rates offered by each of these self-reports are indicative that these tools measure different aspects of the phenomenon, with the two tools that have no underlying theories (i.e., the OEQ and the EDQ) yielding higher prevalence rates than the two tools with underlying addiction theories (i.e., the EAI and the EDS), the latter being the ones most used in research on EA. The EDS and the EAI are focused on dimensions of the multifaceted addictive behaviors. Contrarily, the Compulsory Exercise Test (CET) and its version for athletes (CET-A), as 
Table 1 Features of the main self-reports assessing EA or related constructs

\begin{tabular}{|c|c|}
\hline Measure & Items and subscales/dimensions* \\
\hline OEQ & $\begin{array}{l}\text { 20-21 items assessing cognitions and behaviors underlying the need to engage in } \\
\text { obligatory exercise in } 3 \text { dimensions: fixation, frequency, and commitment }\end{array}$ \\
\hline CES & $\begin{array}{l}8 \text { items in } 2 \text { subscales: obligatory exercise (attitudinal features) and pathological } \\
\text { exercise (behavioral features) }\end{array}$ \\
\hline EDQ & $\begin{array}{l}29 \text { items assessing withdrawal, weight control, positive reward, stereotyped behavior, } \\
\text { interference, insight into problems and health-related motives }\end{array}$ \\
\hline $\mathrm{EDS} / E D S-R \dagger$ & $\begin{array}{l}\text { 28/21 items in } 7 \text { subscales: withdrawal, continuance, tolerance, lack of control, reduc- } \\
\text { tions in other activities, time, and intention. Guidelines for classifying individuals }\end{array}$ \\
\hline EAI & $\begin{array}{l}6 \text { items assessing conflicts, mood modification, tolerance, salience, withdrawal, and } \\
\text { relapse. Cut-offs for classifying individuals }\end{array}$ \\
\hline $\mathrm{CET} / C E T-A \dagger$ & $\begin{array}{l}\text { 24/15 items in } 5 / 3 \text { subscales: avoidance of negative affect and rule-driven behavior, } \\
\text { weight control, mood improvement, lack of enjoyment, and rigidity }\end{array}$ \\
\hline EDEAS/EDEAS-R† & $\begin{array}{l}\text { 27/24 items in } 6 \text { subscales: excessive training/withdrawal, dissatisfaction and conflict, } \\
\text { continuance behaviors, emotional difficulties, desire to engage in more training, and } \\
\text { unhealthy eating behaviors }\end{array}$ \\
\hline ART & $\begin{array}{l}15 \text { items in } 4 \text { subscales: negative affect-driven training, extra training amount, training } \\
\text { against medical advice and body dissatisfaction }\end{array}$ \\
\hline
\end{tabular}

\begin{abstract}
${ }^{*}$ When a measure is unidimensional, the contents covered by the self-report are indicated. $†$ The CET-A includes the CET's items and subscales marked in italics; the EDEAS-R includes the EDEAS items and subscales marked in italics. OEQ=Obligatory Exercise Questionnaire (Blumenthal et al., 1984, rev. Pasman \& Thompson, 1988); CES =Commitment to Exercise Scale (Davis et al., 1993); EDQ =Exercise Dependence Questionnaire (Ogden et al., 1997); EDS = Exercise Dependence Scale (Hausenblas \& Symons Downs, 2002b; revised version by Symons Downs et al., 2004); EAI=Exercise Addiction Inventory (Griffiths et al., 2005; revised version by Szabo et al., 2019); CET=Compulsive Exercise Test (Taranis et al., 2011); CET-A =CET athlete version (Plateau et al., 2014); EDEAS=Exercise Dependence and Elite Athletes Scale (McNamara \& McCabe, 2012; revised version by McNamara \& McCabe, 2013); ART $=$ Athletes' Relationships with Training Scale (Chapa et al., 2018)
\end{abstract}

well as the EDQ, include an array of cognitive, attitudinal, emotional, and behavioral features and manifestations of EA, along with a dimension related to weight control exercise, whereas the OEQ includes only two items concerning compensatory exercise and concerns about body shape, thus poorly measuring weight-related issues, and the CES does not include any item pertaining to body image or eating pathology. Future research is needed to determine which of these measures is more appropriate psychometrically and theoretically, as well as in terms of sensitivity, for the study of both EA and related phenomena such as the dyad EA-eating disorders.

There is also some concern as to whether the current measures of EA are valid for athletes (Müller et al., 2015). The assessment of excessive exercise among athletes is a challenge because, compared to nonathletes, athletes are required to train at higher intensities for longer periods of time and under (almost) any condition (Chapa et al., 2018). Intense exercise and intention effects in this group are more likely due to performance-related reasons than to psychopathology related to exercise behavior (or any other, such as eating behavior and body image disturbances); therefore, high scores may lead to false-positive diagnoses of EA. Thus, measures based exclusively on the amount of exercise performed are poor, do not reflect the complexity and multifaceted nature of EA, and, concretely in the sports context, are totally unreasonable. In addition, most assessment tools have been developed and validated in nonathletic populations and, therefore, do not capture the 
nuances of athletes' training experiences. Along with the adaptation of the CET to athletes (Plateau et al., 2014), there are only two more questionnaires specifically developed for the sports context, namely, the Exercise Dependence and Elite Athletes Scale (EDEAS) and its revised version (McNamara \& McCabe, 2012, 2013) and the Athletes' Relationships with Training Scale (ART) (Chapa et al., 2018). The CET and the ART have as conceptual basis a cognitive behavioral model of EA, whereas the EDEAS was developed based on a biopsychosocial model of exercise dependence. Unfortunately, all of them have been scarcely used but seem promising as they incorporate the main features of EA for athletes plus body image and eating-related issues.

In addition, as Szabo et al. (2015) emphasized, both research and clinical practice have focused on the use of self-reports and questionnaires, which provide a range of risk scores, rather than clinical interviews allowing for a diagnosis. There is also a problematic practice when scoring the self-reports, as researchers use different cut-off criteria (for instance, although guidelines for scoring and interpreting the scores were offered for the EDS, an arbitrary cut-off corresponding to the sample mean has also been used, e.g., Torstveit et al., 2019). Moreover, it is probable that athletes interpret the item content differently than the general population, or the content is differently applicable to both subgroups. It has also been proposed that existing measures may behave differently with female and male respondents (Cook et al., 2013). All of the abovementioned factors occlude a deep understanding of EA and related phenomena, such as its co-occurrence with eating disturbances.

\section{Understanding EA in the Sports Context: from Theory-Guided Research to Empirically Based Practice}

It has been argued that the high prevalence of EA observed among athletes could be simply explained by their higher enrollment in exercise, as well as their higher levels of engagement and commitment because of their involvement in competition, their focus on achieving athletic excellence and the pressure for results (Marques et al., 2019). However, this would only explain why higher prevalence rates of EA have been observed in the athletic population when compared to exercisers or general population samples; it does not allow elucidating either the prevalence rates in the sports context, the variability observed between athletes or the observed heterogeneity in correlates and consequences. Furthermore, it does not address why athletes with EA are so similar in terms of prevalence and psychological features to individuals with disordered eating and eating disorders; we will turn to this below.

Athletes present particular problems in determining their exercise dependence and their correlates as causes or outcomes, since they are required to engage in high levels of exercise as part of their training regime even when they do not feel like doing it, when they are exhausted or injured, when they have other personal life responsibilities or when they are not concerned by their body weight or appearance. Consequently, it is important for empirical studies in this area to be based on a theoretical model of EA (McNamara \& McCabe, 2012). More research is clearly necessary to fully understand the genetic, neurochemical, psychological, and contextual intersected mechanisms implied in EA (Weinstein \& Weinstein, 2014), but a validation of the proposed mechanisms specifically in the athletic population is warranted. Until now, research examining EA has been laden with conceptual limitations, and the lack of a conceptual framework for guiding research leads only to inconclusiveness. 
We agree with the claim made by Meyer and Taranis (2011) that quantitative definitions and models of EA (i.e., in terms of physical activity volume) might be inappropriate for identifying problematic, unhealthy exercise; further, they seem particularly unsuitable for application to athletes due to their unique involvement in training practices. In contrast, qualitative definitions (i.e., in terms of psychological features) would allow for the establishment of pathological markers that are more adequate for distinguishing when an athlete maintains a problematic relationship with exercise and training and even when it is linked to an eating disturbance (see also Dalle Grave et al., 2008). Moreover, as Szabo et al. (2015) stressed, the consequences of behavior are key factors in separating healthy, even exaggerated, patterns of exercise from unhealthy, maladaptive patterns of exercise.

EA is complex and multifaceted, as it encompasses an array of different psychological and physiological characteristics, it originates from the interaction of a multitude of personal and situational factors, and it has varying consequences for an athlete's well-being and athletic performance. Future research on the factors underlying or linked to EA will allow us to generate a conceptual framework for understanding EA in sports (see, e.g., Egorov \& Szabo, 2013 and Szabo et al., 2018 for a review). In such theoretical proposals, the psychological factors involved in EA should be stressed over the physiological factors (Hausenblas \& Symons Downs, 2002a).

As far as we know, to date, three theoretical proposals that were not proposed specifically in the context of sports have been tested in the athletic population and have received some support: the Interactional Model of Exercise Dependence (IMED) by Egorov and Szabo (2013), the Continuum Model of Obligatory Exercise (CMOE) by Elbourne and Chen (2007), and the Cognitive Behavioral Model of Compulsive Exercise (CBMCE) by Meyer et al. (2011). Furthermore, another model was specifically proposed for competitive athletes but has been scarcely investigated to date, namely, the Biopsychosocial Model of Exercise Dependence in Athletes (BMED) by McNamara and McCabe (2012). While the first example does not explicitly incorporate eating dysfunctional behaviors, the remaining models clearly link exercise and eating disturbances in the causal process or the manifestations of EA.

The IMED (Egorov \& Szabo, 2013; see also Szabo et al., 2018) was proposed to explain the adoption, maintenance, and transformation of exercise behavior based on the interaction of several unique personal (e.g., personality, needs and values, interest and goals, skills and abilities) and situational factors (e.g., accessibility and costs, individual/group setting, social factors and values) that influence motivation (i.e., oriented to health, performance or social aspects). Motivational profiles lead in turn to a therapeutic or a mastery orientation to exercise. The basis for the model is, in the authors' words, a misunderstanding of EA as a progression from healthy to unhealthy exercise pattern; contrarily, EA is more revolutionary (suddenly erupting) than evolutionary (slowly building up). As proposed in the model, exercise dependence can occur when, mainly having a therapeutic orientation to exercise, a sudden or progressively intolerable life stress leads to heightened psychological distress, and excessive exercise is used as a way of coping with stress (i.e., an escape).

The IMED was used by Magee et al. (2016) as a framework for understanding exercise dependence among ironman athletes, but it was not tested; however, the authors found that exercise-dependent athletes also reported higher psychological distress compared to athletes with a healthier involvement in sports. Some support was also offered by Back et al. (2019) in a mixed sample of athletes and regular exercisers by finding that anxiety was the main predictor of exercise dependence and that secondary exercise dependence was related to using exercise as a strategy to cope with anxiety. However, other findings are counter to the model's assumptions; for example, EA has been found to be associated with depression 
symptoms but not with anxiety symptoms among amateur and competitive athletes from a variety of individual and team sports (Levit et al., 2018).

A starting point for a theory-based empirical exploration of EA associated with eating pathology was the proposal by Elbourne and Chen (2007) of the CMOE. The CMOE proposed that obligatory exercise is a dynamic process rather than a static entity and lies on a continuum tactivity as a consequence and thus increased obsessivehat is characterized not only by quantitative differences in severity but also by qualitative differences in its manifestations, as behavior progresses from mildly obsessive to extremely disordered attitudes to exercise and compulsive behaviors that are accompanied by an eating disorder. As a continuum, this model runs counter to the proposals of a clear demarcation between primary and secondary obligatory exercise. Based on the loop hypothesis by Davis et al. (1995), whereby physical activity, food restriction, and obsessiveness-compulsiveness potentiate one another in a feedback/feedforward loop, the proposed relationship between EA and disordered eating is also a dynamic process involving the interaction between weight and shape concerns, weight-control actions (i.e., dietary restriction), obsessive-compulsive behaviors, and excessive exercise. Thus, the model holds that at the lower end of the continuum, an individual is committed to exercise with mildly obsessive traits and weight concerns but no signs of a disorder, as these features are rather related to their performance; at the extreme end, an individual is an obligatory exerciser with a marked preoccupation with food and an overconcern with weight and shape, food restriction and increased physical activity as a consequence and thus increased obsessiveness-compulsiveness, which would result in extreme pathological attitudes about exercise and eventually EA, all of which may lead to manifesting a diagnosable eating disorder (i.e., the CMOE establishes a chain of interacting events from body image and weight concerns to EA and then eating disorders). Thus, the CMOE might be useful for studying the co-occurrence of exercise and eating disturbances.

In a study with female triathletes (Elbourne \& Chen, 2007), the main causal postulates of the CMOE were confirmed, yet the interactions among all the variables predicted by the model were not established, thus supporting a simpler chain. The authors confirmed the causal role of weight and shape preoccupation on increased food restriction, which predicted increased obligatory exercise, which along with obsessive-compulsiveness predicted, in turn, disordered eating behaviors. Notably, weight concerns had a core role along the proposed chain of events participating in all the steps. Thus, the authors concluded that the association between obligatory exercise and disordered eating "is a consequence of the fact that they both share common causes, i.e., weight and shape preoccupation" (p. 78).

The CBMCE (Meyer et al., 2011) is another promising model that has been scarcely investigated to date. It is based on the empirically supported relationships between perfectionism and eating psychopathology - note that perfectionism is a key factor in the transdiagnostic model of eating disorders of Fairburn et al. (2003) - , between perfectionism and compulsive exercise, due to shared rigidity and self-criticism, and between compulsive exercise and eating disturbances; such relationships have been established in patients with eating disorders, in the general population and among regular exercisers and athletes. Succinctly, it asserts that perfectionism has a direct relationship with eating pathology but also an indirect association that is mediated by compulsive exercise and its dimensions of (a) exercise driven by rigid rules and avoidance of affective withdrawal symptoms, (b) exercise to control weight, (c) exercise for mood improvement, (d) exercise rigidity, and (e) lack of exercise enjoyment. Thus, compulsive exercise is more than a mere symptom of an eating pathology, participating in the pathogenesis process. In fact, Meyer et al.'s (2011) 
model establishes bidirectional links between compulsive exercise and eating behavior disturbances.

Some support exists for a partial generalizability of the model to the sports context. The model drove the CET measure, which, when applied to athletes, was adapted as the CET-Athlete version (Plateau et al., 2014, 2017). Plateau et al. (2014) found that only the first three abovementioned dimensions were relevant for athletes when investigating the association between EA and eating disorders; among them, only weight control exercise and avoidant exercise predicted eating abnormalities in this population. With the same corrected measure, the model was partially supported in a mixed sample of 18-65-year-old regular exercisers and (possibly competitive) athletes (Egan et al., 2017), where it was found that only the weight control and, contrarily to Plateau et al.'s study, the mood improvement dimensions predicted eating pathology and that only the indirect paths from clinical perfectionism to eating pathology though weight control exercise and mood improvement were significant; in addition, supporting the model predictions, eating pathology was also predicted directly by clinical perfectionism. Egan et al. (2017) concluded based on their cross-sectional findings that, alternatively, compulsive exercise may be a symptom of eating pathology, rather than an antecedent, as dieting and exercise reinforce one another due to social reinforcers that accompany the initial weight loss from regular exercise, which then intensifies eating, shape, and weight concerns. Other findings also seem to partially support the expected relationships. Scott et al., (2020, 2021) found with athletes from lean and non-lean sports that relationships with teammates and team connectedness were associated with reduced disordered exercise behavior and that teammate negative influences on eating and exercise psychopathology were mediated by athletes' psychological distress. Perfectionistic strivings have been found to predict engaging in compulsive exercise for mood improvement, whereas perfectionistic concerns have been found to predict compulsive exercise for both avoiding negative affect and weight control among athletes from several sports (Madigan et al., 2017). With the CET-A, Turton et al. (2017) found in a sample of runners competing in mid- and long distances that athletic identity was associated with higher compulsive exercise, and that, among women, BMI also played a role in the association between athletic identity and weight control exercise, supporting a possible link between EA and eating psychopathology. With the CET, Gorrell and Anderson (2018) found in a similar sample that athletic identity was associated with higher compulsive exercise, and that compulsive exercise was associated with higher eating pathology; nevertheless, it was also found that, among mid-distance runners, both athletic identity and compulsive exercise protected against eating pathology, and that relations between athletic identity and eating disturbances were significant among runners reporting either lower or higher compulsive exercise. Further longitudinal and experimental research is needed to prove the assertions of the model, as well as the paths connecting EA and eating disturbances.

The model by Meyer et al. (2011) has also recently inspired the ART measure (Chapa et al., 2018), specifically made for the athletic population. Chapa and colleagues (2018) were interested in developing and validating a self-report able to capture the unique experiences of athletes with exercise behaviors to distinguish an involvement reflecting healthy athletic training practices that is not counterproductive for optimal performance from beliefs, attitudes, emotions, motivations, and behaviors related to unhealthy involvement, thus incorporating a multidimensional conception of exercise behavior. Ultimately, Chapa et al. (2018) expected to create a useful and clinically valid tool for detecting athletes who have a relationship with training that is indicative of an eating disorder that may warrant 
clinical attention, for tracking clinical outcomes in athletes who are in treatment for an eating disorder and for research purposes.

For that, the authors conceptualized excessive exercise as an eating disorder behavior that facilitates weight control (p. 1081). Although they acknowledged that training to improve performance is likely the primary reason for which athletes exercise, the authors proposed many other motives for engaging in excessive exercise, all of them based on the idea that training might also be viewed as an indirect means to enhance sports performance via weight or body fat loss (e.g., compensating self-perceived excess eating, believing that lower weight leads to better performance, believing that a leaner, thinner body is an advantage in judging in esthetic sports, pursuing the appropriate weight in weight-class sports, having an ideal athletic body). As the authors claimed, existing measures for eating disorders screening in sports do not fully capture the nuances of training behavior in athletes and might not be appropriate for identifying unhealthy exercise, given that such screening (1) usually does not include a dimension regarding excessive exercise and (2) was developed for nonathletic populations, such as clinical samples. Thus, the ART included items assessing attitudes, motives, emotions, and rigidity that were specifically written for the sports environment. The ART has shown appropriate psychometric properties, criterion validity, and sensitivity (Chapa et al., 2018). However, as for the CET, more research is needed on the utility of the ART with more diverse samples in terms of eating disorder status, sports modalities, age/athletic history, competition level and so forth, as well as its incremental validity compared to other EA measures.

Finally, McNamara and McCabe (2012) proposed a biopsychosocial model (BMED) for explaining the development and maintenance of exercise dependence specifically in athletes that, as far as we know, has never been tested except for their study. Based on multidimensional models stating that EA includes a constellation of behavioral factors (e.g., exercise frequency), psychological factors (e.g., pathological commitment, lack of control, preoccupation with body image), physiological factors (e.g., addiction manifestations), and social factors (e.g., social isolation), as well as situational factors (e.g., high level of competition, social pressures), the authors proposed a model that integrates factors relevant for the predisposition, precipitation and perpetuation of EA among high-performance and elite athletes. Briefly, weight (BMI in their proposal) has a peripheral influence on exercise behavior, but it influences both (1) psychological factors, namely, self-esteem and maladaptive beliefs regarding exercise and the varied consequences of not engaging in training, and (2) social forces, namely, pressures from coach and teammates (e.g., to engage in extra training, to improve athletic performance, to train harder, to change body shape and size) and the sociocultural context (e.g., pressures from family, friends, and the media to train, to achieve at a high standard, to be successful at sport, to have an ideal body shape), along with low social support. The interaction of psychological and social factors directly contributes to the risk for and maintenance of exercise dependence. In this model, weight and eating-related pathology are thus conceived as predictors of EA.

In a study among elite athletes, McNamara and McCabe (2012) partially supported the model by using the EDEAS measure, which was specifically designed to cover the factors of EA involved in the model. Furthermore, as BMI was found to be a predictor in the model, the authors concluded that the desire to reduce one's weight may be a motivating factor behind athletes engaging in unhealthy eating and exercise dependence behaviors, such as excessive training. The results suggested that the perceived need to change one's body shape and size may be prominent within athletes who experience exercise dependence, but they are the psychological and the sporting and social contexts which is related to whether weight or body image is a risk factor for the condition. Unfortunately, the authors 
excluded athletes with eating pathology manifestations, precluding further assessment of the model in relation to the co-occurrence of EA and disturbed eating.

Eating disorders at both the clinical and subclinical levels are so prevalent in athletes of any modality, independent of them being more or less sensitive to weight and appearance, i.e., "high-risk" versus "low-risk" sports in classical terms (e.g., Godoy-Izquierdo et al., 2019, for soccer), that such disorders are among the most studied mental disorders in this population. While disordered eating and eating disorders have been widely investigated (see Díaz et al., 2018, for a recent review) and research on EA and the overuse of training is growing, there is still a scarcity of research on the dyad, particularly in the sports context. In this Issue, Godoy-Izquierdo et al. (2021) conducted a systematic review and supported that for many athletes, i.e., up to $80 \%$, EA and eating pathology go hand in hand. Moreover, evidence suggests some overlap in the two dysfunctions, such that athletes displaying symptoms of both exercise and eating pathology may need special attention. The authors also claimed that there is still a long way to go towards fully understanding the causal links of those conditions among athletes, as well as an urgent need for theoretical models that guide future research and empirically based derived clinical practices for detecting, preventing, and managing athletes experiencing the dyad.

\section{Conclusions}

Athletes experience an elevated risk of high-prevalence mental disorders such as depression, anxiety, eating disturbances, and substance abuse; in addition, it seems that there is a positive association among athletic participation and EA, as well as among all the abovementioned conditions and psychological distress, overtraining, burnout, dropout, the premature end of one's sports career, suicide or death (e.g., Bär \& Markser, 2013; Reardon \& Factor, 2010; Rice et al., 2016; Souter et al., 2018). The detection and management of mental and psychopathological issues in athletes cannot be approached without understanding the screening, diagnostic, therapeutic, and preventive issues unique to this population.

High-performance and elite athletes endure a wide array of physical and mental demands and strains that influence their health status and psychological well-being. Among them, those factors derived from the "success" culture of sports and the specific sports context linked to competition and performance, as well as the psychosocial background of each athlete, are the key ingredients to understanding the sport-specific etiology and evolution of mental disturbances in athletes (Bär \& Markser, 2013; Díaz et al., 2018). As Bär and Markser (2013) suggested, the advantages of intensive training, including fitness, enjoyment, and achievement in competition, can turn into threats to health and functioning. Determining the boundary where exercise and training stop being beneficial and begin to impair one's health and performance is a key challenge.

What we know is that there is a subset of individuals for whom exercise can become an obsessive preoccupation and a compulsive involvement to the point where negative health outcomes are experienced at the physical, psychological, and social levels, thereby increasing their vulnerability to injury, ill-being, distress, and even death (Trott et al., 2020). Thus, for caring aims, a distinction is needed to separate those who are highly committed to exercise and those presenting EA.

To fully understand the reality of EA, it is necessary to overcome the criticisms made to date (e.g., Gonçalves et al., 2019; Szabo et al., 2015) by proposing a consensual terminology, operationalization, and measurement of EA, conducting well-controlled empirical 
research on its causes and outcomes, addressing the multiple and varied subjective phenomenological experiences of those suffering from it, and reaching optimal praxis in terms of its diagnosis and clinical practice. For that, it is mandatory to acknowledge that EA is not the same among recreational users of gyms, the general population or athletes pursuing their best performance; similarly, EA is not the same among patients suffering from an eating disorder, regular exercisers who train for appearance goals and athletes who are concerned with their weight and demonstrate dysfunctional eating attitudes and behaviors.

By identifying the attitudinal, cognitive, emotional, motivational, and behavioral features of EA in athletes, screening for detecting individuals who are motivated to exercise on a rigid, compulsive basis (e.g., for weight or mood control) and those with an increased risk for other mental problems, such as eating disorders, can be better approached, and thus, tailored therapy can be provided as soon as possible in order to protect their athletic performance and their well-being.

Author Contribution All authors contributed to the study conception and design, literature search, and data analysis. The first draft of the manuscript was written by DGI and reviewed by the remaining authors. All authors read and approved the final manuscript. DGI and JGH supervised the research process.

Funding Open Access funding provided thanks to the CRUE-CSIC agreement with Springer Nature. This study was funded by the financial aid conceded to the Research Group CTS267 by Junta de Andalucía (Spain). Funding for open access charge: Universidad de Granada/CBUA.

\section{Declarations}

Conflict of Interest The authors declare no competing interests.

Open Access This article is licensed under a Creative Commons Attribution 4.0 International License, which permits use, sharing, adaptation, distribution and reproduction in any medium or format, as long as you give appropriate credit to the original author(s) and the source, provide a link to the Creative Commons licence, and indicate if changes were made. The images or other third party material in this article are included in the article's Creative Commons licence, unless indicated otherwise in a credit line to the material. If material is not included in the article's Creative Commons licence and your intended use is not permitted by statutory regulation or exceeds the permitted use, you will need to obtain permission directly from the copyright holder. To view a copy of this licence, visit http://creativecommons.org/licenses/by/4.0/.

\section{References}

Adams, J. (2009). Understanding exercise dependence. Journal of Contemporary Psychotherapy, 39(4), 231-240. https://doi.org/10.1007/s10879-009-9117-5

Adams, J., \& Kirkby, R. J. (1998). Exercise dependence: A review of its manifestation, theory and measurement. Research in Sports Medicine: An International Journal, 8(3), 265-276. https://doi.org/10.1080/ 15438629809512532

Allegre, B., Souville, M., Therme, P., \& Griffiths, M. (2006). Definitions and measures of exercise dependence. Addiction Research \& Theory, 14(6), 631-646. https://doi.org/10.1080/16066350600903302

Back, J., Josefsson, T., Ivarsson, A., \& Gustafsson, H. (2019). Psychological risk factors for exercise dependence. International Journal of Sport and Exercise Psychology. https://doi.org/10.1080/16121 97X.2019.1674902

Bär, K. J., \& Markser, V. Z. (2013). Sport specificity of mental disorders: The issue of sport psychiatry. European Archives of Psychiatry and Clinical Neuroscience, 263(S2), 205-210. https://doi.org/10. 1007/s00406-013-0458-4

Berczik, K., Szabó, A., Griffiths, M. D., Kurimay, T., Kun, B., Urbán, R., \& Demetrovics, Z. (2012). Exercise addiction: Symptoms, diagnosis, epidemiology, and etiology. Substance Use \& Misuse, 47(4), 403-417. https://doi.org/10.3109/10826084.2011.639120 
Blaydon, M. J., Lindner, K. J., \& Kerr, J. H. (2002). Metamotivational characteristics of eating-disordered and exercise-dependent triathletes: An application of reversal theory. Psychology of Sport and Exercise, 3(3), 223-236. https://doi.org/10.1016/S1469-0292(01)00021-8

Blaydon, M. J., Linder, K. J., \& Kerr, J. H. (2004). Metamotivational characteristics of exercise dependence and eating disorders in highly active amateur sport participants. Personality and Individual Differences, 36(6), 1419-1432. https://doi.org/10.1016/S0191-8869(03)00238-1

Chang, C. J., Putukian, M., Aerni, G., Diamond, A. B., Hong, E. S., Ingram, Y. M., ... \& Wolanin, A. T. (2020). American Medical Society for Sports Medicine Position Statement: Mental health issues and psychological factors in athletes: detection, management, effect on performance, and prevention-Executive summary. Clinical Journal of Sport Medicine, 30(2), 91-95. https://doi.org/10.1097/JSM.00000 00000000799

Chapa, D. A., Hagan, K. E., Forbush, K. T., Perko, V. L., Sorokina, D. A., Alasmar, A. Y., ... \& Stewart, T. M. (2018). The Athletes' Relationships with Training scale (ART): a self-report measure of unhealthy training behaviors associated with eating disorders. International Journal of Eating Disorders, 51(9), 1080-1089. https://doi.org/10.1002/eat.22960

Cook, B., Hausenblas, H., \& Freimuth, M. (2014). Exercise addiction and compulsive exercising: Relationship to eating disorders, substance use disorders and addictions. In T. D. B. Brewerton (Ed.), Eating disorders, addictions and substance use disorders research, clinical and treatment perspectives (pp. 127-144). Springer.

Cook, B., Karr, T. M., Zunker, C., Mitchell, J. E., Thompson, R., Sherman, R., ... \& Wonderlich, S. A. (2013). Primary and secondary exercise dependence in a community-based sample of road race runners. Journal of Sport and Exercise Psychology, 35(5), 464-469. https://doi.org/10.1123/jsep. 35.5 .464

Cook, B., \& Luke, R. (2017). Primary and secondary exercise dependence in a sample of cyclists. International Journal of Mental Health and Addiction, 15(2), 444-451. https://doi.org/10.1007/ s1 1469-017-9745-z

Costa, S., Hausenblas, H. A., Oliva, P., Cuzzocrea, F., \& Larcan, R. (2015). Perceived parental psychological control and exercise dependence symptoms in competitive athletes. International Journal of Mental Health \& Addiction, 13(1), 59-72. https://doi.org/10.1007/s11469-014-9512-3

Cunningham, H. E., Pearman, S., \& Brewerton, T. D. (2016). Conceptualizing primary and secondary pathological exercise using available measures of excessive exercise. International Journal of Eating Disorders, 49(8), 778-792. https://doi.org/10.1002/eat.22551

Dalle Grave, R., Calugi, S., \& Marchesini, G. (2008). Compulsive exercise to control shape or weight in eating disorders: Prevalence, associated features, and treatment outcome. Comprehensive Psychiatry, 49(4), 346-352. https://doi.org/10.1016/j.comppsych.2007.12.007

Davis, C. (2000). Exercise abuse. International Journal of Sport Psychology, 31(2), 278-289.

Davis, C., Brewer, H., \& Ratusny, D. (1993). Behavioral frequency and psychological commitment: Necessary concepts in the study of excessive exercising. Journal of Behavioral Medicine, 16(6), 611-628. https://doi.org/10.1007/BF00844722

Davis, C., Kennedy, S. H., Ralevski, E., Dionne, M., Brewer, H., Neitzert, C., \& Ratusny, D. (1995). Obsessive compulsiveness and physical activity in anorexia nervosa and high-level exercising. Journal of Psychosomatic Research, 39(8), 967-976. https://doi.org/10.1016/0022-3999(95)00064-X

Díaz, I., Godoy-Izquierdo, D., Navarrón, E., Ramírez, M. J., \& Dosil, J. (2018). Eating disorders in sports and football: An updated review. Cuadernos De Psicología Del Deporte, 18(2), 45-56.

Di Lodovico, L., Poulnais, S., \& Gorwood, P. (2019). Which sports are more at risk of physical exercise addiction: A systematic review. Addictive Behaviors, 93, 257-262. https://doi.org/10.1016/j.addbeh.2018.12.030

Egan, S. J., Bodill, K., Watson, H. J., Valentine, E., Shu, C., \& Hagger, M. S. (2017). Compulsive exercise as a mediator between clinical perfectionism and eating pathology. Eating Behaviors, 24, 11-16. https://doi.org/10.1016/j.eatbeh.2016.11.001

Egorov, A. Y., \& Szabo, A. (2013). The exercise paradox: An interactional model for a clearer conceptualization of exercise addiction. Journal of Behavioral Addictions, 2(4), 199-208. https://doi.org/10. 1556/JBA.2.2013.4.2

Elbourne, K. E., \& Chen, J. (2007). The continuum model of obligatory exercise: A preliminary investigation. Journal of Psychosomatic Research, 62(1), 73-80. https://doi.org/10.1016/j.jpsychores. 2004.12.003

Fairburn, C. G., Cooper, Z., \& Shafran, R. (2003). Cognitive behaviour therapy for eating disorders: A "transdiagnostic" theory and treatment. Behaviour Research and Therapy, 41(5), 509-528. https:// doi.org/10.1016/S0005-7967(02)00088-8 
Freimuth, M., Moniz, S., \& Kim, S. R. (2011). Clarifying exercise addiction: Differential diagnosis, cooccurring disorders, and phases of addiction. International Journal of Environmental Research and Public Health, 8(10), 4069-4081. https://doi.org/10.3390/ijerph8104069

Gapin, J. I., \& Petruzzello, S. J. (2011). Athletic identity and disordered eating in obligatory and nonobligatory runners. Journal of Sports Sciences, 29(10), 1001-1010. https://doi.org/10.1080/02640 414.2011.571275

Godoy-Izquierdo, D., Díaz, I., Ramírez, M. J., Navarrón, E., \& Dosil, J. (2019). Risk for eating disorders in "high"- and "low"- risk sports and football (soccer): A profile analysis with clustering techniques. Revista De Psicología Del Deporte, 28(2), 117-126.

Godoy-Izquierdo, D., Ramírez, M. J., López-Mora, C., \& Díaz, I. (2021). A systematic review on exercise addiction and the disordered eating-eating disorders continuum in the competitive sport context. International Journal of Mental Health and Addiction. https://doi.org/10.1007/ s11469-021-00610-2

Gonçalves, J., Costa, P. N., Faria, M., \& do Espírito-Santo, G., Assis, M., \& Palma, A. . (2019). Exercise dependence: An updated systematic review. Journal of Exercise Physiology Online, 22(5), $105-125$.

Gorrell, S., \& Anderson, D. A. (2018). Athlete identity and eating pathology in distance runners: When compulsive exercise matters. Journal of Clinical Sport Psychology, 12(4), 647-657. https://doi.org/ 10.1123/jcsp.2018-0016

Griffiths, M. D., Szabo, A., \& Terry, A. (2005). The Exercise Addiction Inventory: A quick and easy screening tool for health practitioners. British Journal of Sports Medicine, 39(6), e30. https://doi. org/10.1136/bjsm.2004.017020

Hausenblas, H. A., \& Symons Downs, D. (2002a). Exercise dependence: A systematic review. Psychology of Sport and Exercise, 3(2), 89-123. https://doi.org/10.1016/S1469-0292(00)00015-7

Hausenblas, H. A., \& Symons Downs, D. (2002b). How much is too much? The development and validation of the exercise dependence scale. Psychology and Health, 17(4), 387-404. https://doi.org/10. 1080/0887044022000004894

Henriksen, K., Schinke, R., Moesch, K., McCann, S., Parham, W. D., Larsen, C. H., \& Terry, P. (2019). Consensus statement on improving the mental health of high performance athletes. International Journal of Sport and Exercise Psychology. https://doi.org/10.1080/1612197X.2019.1570473

Johnston, O., Reilly, J., \& Kremer, J. (2011). Excessive exercise: From quantitative categorisation to a qualitative continuum approach. European Eating Disorders Review, 19(3), 237-248. https://doi. org/10.1002/erv.970

Kerr, J. H., Lindner, K. J., \& Blaydon, M. (2007). Exercise dependence. Routledge.

Lease, H. J., \& Bond, M. J. (2013). Correspondence between alternate measures of maladaptive exercise, and their associations with disordered eating symptomatology. Journal of Behavioral Addictions, 2(3), 153-159. https://doi.org/10.1556/JBA.2.2013.012

Levit, M., Weinstein, A., Weinstein, Y., Tzur-Bitan, D., \& Weinstein, A. (2018). A study on the relationship between exercise addiction, abnormal eating attitudes, anxiety and depression among athletes in Israel. Journal of Behavioral Addictions, 7(3), 800-805. https://doi.org/10.1556/2006.7.2018.83

Lichtenstein, M. B., Hinze, C. J., Emborg, B., Thomsen, F., \& Hemmingsen, S. D. (2017). Compulsive exercise: Links, risks and challenges faced. Psychology Research and Behavior Management, 10, 85-95. https://doi.org/10.2147/PRBM.S113093

Lichtenstein, M. B., Larsen, K. S., Christiansen, E., Støving, R. K., \& Bredahl, T. V. G. (2014). Exercise addiction in team sport and individual sport: Prevalences and validation of the exercise addiction inventory. Addiction Research \& Theory, 22(5), 431-437. https://doi.org/10.3109/16066359.2013. 875537

Madigan, D. J., Stoeber, J., \& Passfield, L. (2017). Athletes' perfectionism and reasons for training: Perfectionistic concerns predict training for weight control. Personality and Individual Differences, 115, 133-136. https://doi.org/10.1016/j.paid.2016.03.034

Magee, C. A., Buchanan, I., \& Barrie, L. (2016). Profiles of exercise dependence symptoms in Ironman participants. Psychology of Sport and Exercise, 24, 48-55. https://doi.org/10.1016/j.psychsport. 2016.01.005

Marques, A., Peralta, M., Sarmento, H., Loureiro, V., Gouveia, E. R., \& de Matos, M. G. (2019). Prevalence of risk for exercise dependence: A systematic review. Sports Medicine, 49(2), 319-330. https://doi.org/10.1007/s40279-018-1011-4

McNamara, J., \& McCabe, M. P. (2012). Striving for success or addiction? Exercise dependence among elite Australian athletes. Journal of Sports Sciences, 30(8), 755-766. https://doi.org/10.1080/02640 414.2012.667879 
McNamara, J., \& McCabe, M. P. (2013). Development and validation of the exercise dependence and elite athletes scale. Performance Enhancement \& Health, 2(1), 30-36. https://doi.org/10.1016/j. peh.2012.11.001

Meyer, C., \& Taranis, L. (2011). Exercise in the eating disorders: Terms and definitions. European Eating Disorders Review, 19(3), 169-173. https://doi.org/10.1002/erv.1121

Meyer, C., Taranis, L., Goodwin, H., \& Haycraft, E. (2011). Compulsive exercise and eating disorders. European Eating Disorders Review, 19(3), 174-189. https://doi.org/10.1002/erv.1122

Modolo, V. B., Antunes, H. K., Gimenez, P. R., Santiago, M. L., Tufik, S., \& Mello, M. T. (2011). Negative addiction to exercise: Are there differences between genders? Clinics (são Paulo, Brazil), 66(2), 255-260. https://doi.org/10.1590/S1807-59322011000200013

Moesch, K., Kenttä, G., Kleinert, J., Quignon-Fleuret, C., Cecil, S., \& Bertollo, M. (2018). FEPSAC position statement: Mental health disorders in elite athletes and models of service provision. Psychology of Sport and Exercise, 38, 61-71. https://doi.org/10.1016/j.psychsport.2018.05.013

Mudry, T. E., Hodgins, D. C., \& el-Guebaly, N., Cameron Wild, T., Colman, I., Patten, S. B., \& Schopflocher, D. . (2011). Conceptualizing excessive behaviour syndromes: A systematic review. Current Psychiatry Reviews, 7(2), 138-151. https://doi.org/10.2174/157340011796391201

Müller, A., Claes, L., Wos, K., Kerling, A., Wünsch-Leiteritz, W., Cook, B., \& de Zwaan, M. (2015). Temperament and risk for exercise dependence: Results of a pilot study in female patients with eating disorders compared to elite athletes. Psychopathology, 48(4), 264-269. https://doi.org/10.1159/ 000436978

Nogueira, A., Molinero, O., Salguero, A., \& Márquez, S. (2018). Exercise addiction in practitioners of endurance sports: A literature review. Frontiers in Psychology, 9, 1484. https://doi.org/10.3389/ fpsyg.2018.01484

Ogden, J., Veale, D. M. W., \& Summers, Z. (1997). The development and validation of the Exercise dependence Questionnaire. Addiction Research, 5(4), 343-356. https://doi.org/10.3109/16066 359709004348

Pasman, L., \& Thompson, J. K. (1988). Body image and eating disturbances in obligatory runners, obligatory weightlifters, and sedentary individuals. International Journal of Eating Disorders, 7(6), 759769. https://doi.org/10.1002/1098-108X(198811)7:6\%3c759::AID-EAT2260070605\%3e3.0.CO;2-G

Petit, A., \& Lejoyeux, M. (2013). Exercise addiction. Revue Medicale De Liege, 68(5-6), 331-339.

Plateau, C. R., Arcelus, J., \& Meyer, C. (2017). Detecting eating psychopathology in female athletes by asking about exercise: Use of the Compulsive Exercise Test. European Eating Disorders Review, 25(6), 618-624. https://doi.org/10.1002/erv.2561

Plateau, C. R., Shanmugam, V., Duckham, R. L., Goodwin, H., Jowett, S., Brooke-Wavell, K. S. F., ... \& Meyer, C. (2014). Use of the compulsive exercise test with athletes: norms and links with eating psychopathology. Journal of Applied Sport Psychology, 26(3), 287-301. https://doi.org/10.1080/ 10413200.2013.867911

Reardon, C. L., \& Factor, R. M. (2010). Sport psychiatry. Sports Medicine, 40(11), 961-980. https://doi. org/10.2165/11536580-000000000-00000

Reardon, C. L., Hainline, B., Aron, C. M., Baron, D., Baum, A. L., Bindra, A., ... \& Derevensky, J. L. (2019). Mental health in elite athletes: International Olympic Committee consensus statement (2019). British Journal of Sports Medicine, 53(11), 667-699. https://doi.org/10.1136/bjsports-2019-100715

Rice, S. M., Purcell, R., De Silva, S., Mawren, D., McGorry, P. D., \& Parker, A. G. (2016). The mental health of elite athletes: A narrative systematic review. Sports Medicine, 46(9), 1333-1353. https:// doi.org/10.1007/s40279-016-0492-2

Schinke, R. J., Stambulova, N. B., Si, G., \& Moore, Z. (2018). International society of sport psychology position stand: Athletes' mental health, performance, and development. International Journal of Sport and Exercise Psychology, 16(6), 622-639. https://doi.org/10.1080/1612197X.2017.1295557

Scott, C. L., Haycraft, E., \& Plateau, C. R. (2021). The influence of social networks within sports teams on athletes' eating and exercise psychopathology: A longitudinal study. Psychology of Sport and Exercise, 52, 101786. https://doi.org/10.1016/j.psychsport.2020.101786

Scott, C. L., Plateau, C. R., \& Haycraft, E. (2020). Teammate influences, psychological well-being, and athletes' eating and exercise psychopathology: A moderated mediation analysis. International Journal of Eating Disorders, 53(4), 564-573. https://doi.org/10.1002/eat.23222

Simón-Grima, J., Estrada-Marcén, N., \& Montero-Marín, J. (2019). Adicción al ejercicio medida a través del Exercise Addiction Inventory (EAI) y salud en deportistas habituales. Una Revisión Sistemática y Meta-Análisis. Adicciones, 31(3), 233-249.

Souter, G., Lewis, R., \& Serrant, L. (2018). Men, mental health and elite sport: A narrative review. Sports Medicine-Open, 4(1), 57. https://doi.org/10.1186/s40798-018-0175-7 
Symons Downs, D., Hausenblas, H., \& Nigg, C. (2004). Factorial validity and psychometric examination of the exercise dependence scale-revised. Measurement in Physical Education and Exercise Science, 84(4), 183-201. https://doi.org/10.1207/s15327841mpee0804_1

Szabo, A. (2009). Addiction to exercise: a symptom or a disorder? In C. H. Chan (Ed.), Handbook of sports psychology. Sports and Athletics Preparation Performance and Psychology (pp. 123-170). Nova Science Publishers.

Szabo, A., Demetrovics, Z., \& Griffiths, M. D. (2018). Morbid exercise behavior: Addiction or psychological escape? In H. Budde \& M. Wegner (Eds.), The exercise effect on mental health: Neurobiological mechanisms (pp. 277-311). Taylor and Francis.

Szabo, A., Griffiths, M. D., De La Vega Marcos, R., Mervó, B., \& Demetrovics, Z. (2015). Methodological and conceptual limitations in exercise addiction research. The Yale Journal of Biology \& Medicine, 88(3), 303-308. https://doi.org/10.1186/s40798-014-0005-5

Szabo, A., Pinto, A., Griffiths, M., Kovácsik, R., \& Demetrovics, Z. (2019). The psychometric evaluation of the Revised Exercise Addiction Inventory: Improved psychometric properties by changing item response rating. Journal of Behavioral Addictions, 8(1), 157-161. https://doi.org/10.1556/ 2006.8.2019.06

Taranis, L., Touyz, S., \& Meyer, C. (2011). Disordered eating and exercise: Development and preliminary validation of the Compulsive Exercise Test (CET). European Eating Disorders Review, 19(3), 256268. https://doi.org/10.1002/erv.1108

Torstveit, M. K., Fahrenholtz, I. L., Lichtenstein, M. B., Stenqvist, T. B., \& Melin, A. K. (2019). Exercise dependence, eating disorder symptoms and biomarkers of Relative Energy Deficiency in Sports (REDS) among male endurance athletes. BMJ Open Sport \& Exercise Medicine, 5(1), e000439. https://doi. org/10.1136/bmjsem-2018-000439

Trott, M., Jackson, S. E., Firth, J., Jacob, L., Grabovac, I., Mistry, A., ... \& Smith, L. (2020). A comparative meta-analysis of the prevalence of exercise addiction in adults with and without indicated eating disorders. Eating and Weight Disorders-Studies on Anorexia, Bulimia and Obesity. https://doi.org/10.1007/ s40519-019-00842-1

Turton, R., Goodwin, H., \& Meyer, C. (2017). Athletic identity, compulsive exercise and eating psychopathology in long-distance runners. Eating Behaviors, 26, 129-132. https://doi.org/10.1016/j.eatbeh. 2017.03.001

Veale, D. M. (1987). Exercise dependence. British Journal of Addiction, 82(7), 735-740. https://doi.org/10. 1111/j.1360-0443.1987.tb01539.x

Weinstein, A., \& Weinstein, Y. (2014). Exercise addiction-diagnosis, bio-psychological mechanisms and treatment issues. Current Pharmaceutical Design, 20(25), 4062-4069. https://doi.org/10.2174/13816 128113199990614

Yates, A., Leehey, K., \& Shisslak, C. M. (1983). Running — an analogue of anorexia? New England Journal of Medicine, 308(5), 251-255. https://doi.org/10.1056/NEJM198302033080504

Zeeck, A., Schlegel, S., Giel, K. E., Junne, F., Kopp, C., Joos, A., ... \& Hartmann, A. (2017). Validation of the German version of the commitment to exercise scale. Psychopathology, 50(2), 146-156. https://doi. org/10.1159/000455929

Publisher's Note Springer Nature remains neutral with regard to jurisdictional claims in published maps and institutional affiliations. 